\title{
What do Malawi Polytechnic first year students know and do about HIV and AIDS?
}

\section{S. Kumwenda*, C.Kambala, C.Mwendera, K. Kalulu}

Department of Environmental Health, The Polytechnic, University of Malawi

*Correspondence to: savekumwenda@yahoo.com

\section{Abstract}

\section{Background}

The Polytechnic introduced a "WHY WAIT?" course to equip first year students with skills to help reduce transmission of Human Immune-deficiency Virus (HIV). Training is conducted during the first week of arrival at college. The study aimed to explore existing knowledge, beliefs and attitudes in order to tailor the training programme to students' needs.

\section{Methods}

This was a cross sectional study. During first day of arrival, first year students available on campus were given a structured selfadministered questionnaire which was filled and submitted before the course. Out of 320 questionnaires distributed, 295 were returned representing $92 \%$ response rate.

\section{Results}

Ten percent (30) had more than one girlfriend or boyfriend. Ninety-seven percent (286) indicated that condoms are not 100\% effective towards prevention of HIV while $72 \%$ (169) reported that they had never had sexual intercourse before. Of 66 students who had had sexual intercourse before, 30\% indicated that they used condoms always during sexual intercourse, $40 \%$ used it occasionally while $30 \%$ never used condoms. Thirty-two percent (94) reported having an HIV test before and 19\% (56) would feel uncomfortable to share a room with an HIV infected person.

\section{Conclusion}

The Polytechnic first year students have varying knowledge and practices about HIV and AIDS. There is need to intensify "WHY WAIT?" course to first years during first week at College to help equip them with necessary knowledge and skills to protect themselves against HIV and AIDS.

\section{Introduction}

Over the years HIV continues to rapidly spread in different groups of people including children, youth and adults throughout the world. Youth are more vulnerable to HIV infection when compared to the other age groups, such that over half of all new infections worldwide are among young people aged 15 to 24 years $^{1}$. It is estimated that 6000 young people become infected with HIV daily ${ }^{2}$. Therefore young people need to be helped to identify and acquire the life skills they need to overcome complex problems resulting from HIV and AIDS in order to enjoy their life to the full and avoid the worst disasters ${ }^{3,4}$. Young people will contribute not only to development of their own families and communities but also to the development of their countries ${ }^{4}$. Those who learn to avoid risky behaviors such as smoking, alcohol and drug abuse, and sex with multiple partners, will not be a burden on the social and health services of the country. They will have skills to prevent acquiring HIV and if they already have the infection will avoid transmission and also live a positive life. These young people will also be able to pass on their skills to their peers ${ }^{5}$.

Malawi's first Acquired Immune Deficiency Syndrome (AIDS) case was reported in 1985. Currently, the Human Immune-deficiency Virus (HIV) prevalence is at $12 \%$ and is among the highest in the world ${ }^{6,7}$. The prevalence is high especially among the adolescents and youth, particularly those between the ages of 13 and $24^{7,8}$. The youth living with HIV in Malawi in 2004 were more likely to have been more recently infected compared with adults ${ }^{9}$. Overall, 6\% of youth were infected with HIV in Malawi in 2004. Prevalence of HIV was more than four times higher among young women than among young men ( $9 \%$ compared with $2 \%)^{9}$. The prevalence of HIV in the urban areas was similar to that in rural areas ( 7 and $6 \%$, respectively). Heterosexual contact is the principal mode of HIV transmission, while mother-tochild transmission (MTCT) accounts for about 25\% of all new HIV infections 9 . The epidemic kills approximately eight people every hour in Malawi and about one million people out of a population of approximately 14 million were living with HIV at the end of 2007 globally ${ }^{7,8}$.

The University of Malawi introduced the "WHY WAIT?" programme to all first year students in all the constituent colleges in 2010. This is a two day training course of first year students during their first week at College. It aims to equip students to avoid HIV transmission and risky behaviours which may be aggravated by College environment like the freedom to associate between boys and girls which is absent in Secondary schools and peer pressure ${ }^{5}$. The programme is based on the workbook called "Truth for Youth Life Skills Curriculum for Post-Secondary Institutions, Student's Workbook" by Moira Chimombo of Sub-Saharan Africa Family Enrichment (SAFE) in Zomba, Malawi. The workbook is dedicated to: "the next generation of Africa, with the expectation that they will reverse the current devastation of AIDS and to the teachers who are committed to guiding them in God's principles of life"5. The WHY WAIT? Course curriculum is designed to start with a precourse survey before delivery of the course. This study was done to discover what first year students already know and do before starting University life. This will help appropriate review of the WHY WAIT? course in line with needs of students.

\section{Methodology}

A cross sectional study was done before a "WHY WAIT?" course was delivered to first year students at the Polytechnic. The aim of the study was to establish the existing knowledge, attitudes, beliefs and practices of students on HIV and AIDS and the existing risky behaviours. Such surveys are important before implementation of a programme as they help in proper target setting ${ }^{10}$. During the first and second day of arrival at the campus, all first years (both residential and non residential) present, were given a structured self-administered questionnaire ${ }^{5}$, which was filled and submitted before the life skills course started. The total number of first years selected at The Polytechnic during the year 2009/2010 was 570 . 
At the time of study 320 students who were available on campus were issued with a questionnaire each. Out of 320 questionnaires distributed, 295 were returned representing a response rate of $92 \%$. Consent was sought from University administration and from the students before filling in the questionnaire. The questionnaire among others covered general knowledge on HIV and AIDS, risky behaviours that may increase chances of getting HIV, attendance of any course/workshop on HIV and AIDS, life skills and sex education, ways of HIV transmission and beliefs and attitudes towards HIV and AIDS. Qualitative data was analyzed manually through the use of thematic analysis. Data obtained from open ended questions was summarized according to thematic areas of interest. Themes and subthemes were induced from the summary notes and ranked according to their importance. Significant quotes were noted and have been highlighted below.

\section{Results}

\section{Demographic characteristics}

Of the 295 respondents who participated in the study, $42 \%$ were females, 55\% were males and 3\% respondents did not indicate their sex. Most of the students (288) reported being single, three were married, three were widowed and one was divorced. The mean age was $19 \pm 2.17$ years. The majority (96\%) of respondents was Christian, 3\% were Muslims and $1 \%$ had no religion.

\section{Behaviours of students that may predispose students to HIV}

Of the 295 respondents, 9\% (27) reported drinking alcohol, $3 \%$ (9) said they smoked cigarettes or Indian hemp. At least $45 \%$ (133) of the respondents had a girlfriend or boyfriend either at The Polytechnic or outside the college and 10\% (30) had more than one girlfriend or boyfriend. Behaviours such as having more than one girl/boyfriends, smoking and drinking alcohol were not related to perception of being at risk and also the taking of an HIV test $(p>0.05)$. Figure 1 shows the participants experience with regard to history of attendance of workshops or courses on HIV and AIDS, life skills and sex education.

Figure 1: Previous attendance of workshops or courses on HIV and ATDS, life skills and sex education

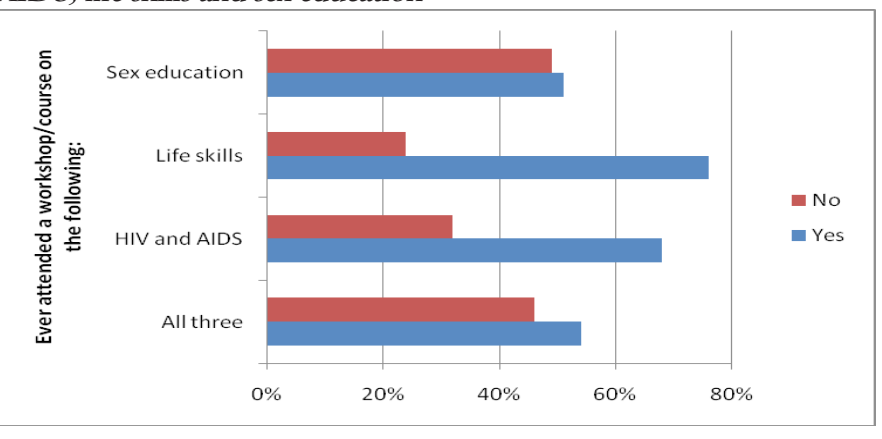

More than half of the responding students had attended workshops and/or courses on HIV and AIDS, life skills and/or sex education (54\%). Having attended a course or workshop on HIV and AIDS was not related to having an HIV test $(p=0.05)$. There was also no relationship between attending any workshop/course on HIV and AIDS, life skills or sex education or on all the three and the perception of being at risk of HIV or having an HIV test ( $p>0.05)$.On whether they are at risk of contracting HIV or not, $81 \%$
(235) indicated that they are not at risk while 19\% (56) indicated that they are at risk. Almost all respondents $(97 \%$, $285)$ indicated that condoms are not $100 \%$ effective towards prevention of HIV except 3\% (10) who said they are 100\% effective.

On possible ways of HIV transmission, students were asked whether some statements included in the questionnaire were true or false. The summary of the responses given by the students are presented in Table 1 below:

Table 1: Knowledge levels on HIV transmission ways among first year students at the Polytechnic, Malawi

\begin{tabular}{|l|l|l|}
\hline $\begin{array}{l}\text { Ways of HIV Trans } \\
\text { mission }\end{array}$ & True & False \\
\hline Kissing & $20 \%$ & $80 \%$ \\
\hline $\begin{array}{l}\text { Coughing or } \\
\text { sneezing }\end{array}$ & $2 \%$ & $98 \%$ \\
\hline Sexual intercourse & $95 \%$ & $5 \%$ \\
\hline $\begin{array}{l}\text { Sharing plates, cups, } \\
\text { cutlery }\end{array}$ & $4 \%$ & $96 \%$ \\
\hline Having one's hair cut & $19 \%$ & $81 \%$ \\
\hline Blood transfusions & $92 \%$ & $8 \%$ \\
\hline Animals & $6 \%$ & $94 \%$ \\
\hline Touching fresh blood & $61 \%$ & $39 \%$ \\
\hline $\begin{array}{l}\text { Mosquitoes and } \\
\text { other insects }\end{array}$ & $8 \%$ & $92 \%$ \\
\hline From mother to baby & $90 \%$ & $10 \%$ \\
\hline $\begin{array}{l}\text { Living with a person } \\
\text { who has AlDS }\end{array}$ & $6 \%$ & $94 \%$ \\
\hline Injections & $88 \%$ & $12 \%$ \\
\hline $\begin{array}{l}\text { Sharing towels or } \\
\text { clothes }\end{array}$ & $2 \%$ & $98 \%$ \\
\hline Ear-piercing & $5 \%$ & $95 \%$ \\
\hline Tattooing & $81 \%$ & $19 \%$ \\
\hline $\begin{array}{l}\text { Circumcision or } \\
\text { memale genital } \\
\text { mutilation }\end{array}$ & $52 \%$ & $48 \%$ \\
\hline
\end{tabular}

When the respondents were asked the advantages of knowing one's HIV status, 35\% of the respondents stated that knowing ones status helps people to plan for their future; $26 \%$ felt that it gives them knowledge of how to take care of oneself; $22 \%$ indicated that one can access ARVs in good time; and 9\% thought the advantage was that once one is found positive he or she may live positively. These comments illustrate some of the things that were written by some students:

"It gives you a chance to take precautions or receive medical care"

"Take right action and strategies accordingly-free the mind of anxiety of the unknown or false hopes"

Equally if people know their status they may change their behaviors:

"Change their ways of living"

Others felt it is good for the government:

"For the government to know how many people are infected"

On the contrary other people did not know whether knowing your status has any advantages:

"I don't know and I doubt if there is any" 
When respondents were asked to mention the disadvantages of knowing one's HIV status, there were some disparities between people's recognition of the advantages and the disadvantages. For example although 35\% thought planning for your future is an advantage for knowing your status, about $32 \%$ saw this as a disadvantage as stated by one respondent: "It's like the future is doomed"

About $12 \%$ thought that if you know your HIV status, particularly if you are positive this may lead to an early death mostly because many will think of committing suicide because they feel that is the end of their life:

"You can kill yourself because of worrying"

Some $(8 \%)$ thought that if other people are found positive they may decide to spread it. They may now lead a reckless life and spread the disease to innocent people as stated below:

"May decide to spread the virus if positive"

"Having multiple partners to spread it if infected"

Other implications for knowing one's status included that it may lead to depression, stress, low self-esteem, psycho-social problems as well as stigma:

"Being subjected to rejection and laughing stock among persons"

"May lead to worries and stigma"

"Some get affected psychologically and do the unthinkable e.g. murder"

\section{Perceptions, Attitudes and Beliefs on HIV and AIDS}

In order to gain an understanding of the respondents' perceptions on the risk of contracting HIV, they were asked to express whether they thought they may be at risk of contracting HIV. Respondents did not share the same perceptions; they had a variety of ideas that were expressed. It is suggested that the opinions expressed were a result of the different individual experiences. There were five main opinions that were common to the majority of the 54 students who responded. About 15\% thought they were at risk of contracting HIV because of road accidents and being exposed to blood, $17 \%$ due to poor condom usage, $13 \%$ because of having unprotected sex, $8 \%$ being unfaithful to one's partner and $11 \%$ thought they might get HIV through blood transfusion. The responses included:

"It may be accidentally contracted during a road accident"

"Don't know how to use a condom"

"Broken condom"

Some of the respondents seem not to understand whether they are at risk as their responses were as follows:

"I am surrounded by the vectors of AIDS"

"I know myself"

"May be infected through unknown ways"

Despite concerns that were expressed by some respondents on the possibility of being at risk of HIV contraction, most respondents indicated that they abstain from sex (38 of 54) and indicated that they have knowledge on how to prevent HIV; therefore they are not at risk of contracting it. This was evident in their responses as follows:

"I know the ways of preventing it and the effects of it if one does contract it"

"I have learnt a lot about the disease"

"T have adequate information that can belp me not to be at risk."

Other reasons that were identified for not being at risk of

HIV contraction included beliefs, being religious as well as maturity. Faithfulness to your partner was also seen as desirable. The beliefs were shown in the following quotes:
"I have beliefs I stick to so much"

"T believe I will be able to stick to my values"

"Because of my morally upright resolution that I live by"

"Am walking with the Lord"

"I am a believer and will always be led by Jesus Christ"

"Because I am a church boy"

Other nine respondents felt confident that they may not be at risk because they protect themselves. As expressed by one respondent:

"I protect myself at all cost"

Table 2: Attitudes towards various HIV and AIDS issues as expressed by Polytechnic students, $n=295$

\begin{tabular}{|l|l|l|}
\hline & True & False \\
\hline $\begin{array}{l}\text { I would feel uncom } \\
\text { fortable being taught } \\
\text { by a person living } \\
\text { with HIV and AIDS. }\end{array}$ & $7 \%$ & $93 \%$ \\
\hline $\begin{array}{l}\text { I would feel uncom } \\
\text { fortable sitting next } \\
\text { to a person living } \\
\text { with HIV and AIDS } \\
\text { in the classroom. }\end{array}$ & $11 \%$ & $89 \%$ \\
\hline $\begin{array}{l}\text { I would feel uncom } \\
\text { fortable sharing a } \\
\text { room with a person } \\
\text { living with HIV and } \\
\text { AIDS. }\end{array}$ & $19 \%$ & $81 \%$ \\
\hline $\begin{array}{l}\text { A person living with } \\
\text { HIV and AIDS } \\
\text { deserves what she } \\
\text { or he gets }\end{array}$ & $18 \%$ & $82 \%$ \\
\hline $\begin{array}{l}\text { Having sexual inter } \\
\text { course before } \\
\text { marriage is okay. }\end{array}$ & $15 \%$ & $85 \%$ \\
\hline $\begin{array}{l}\text { People living with } \\
\text { HIV and AIDS should } \\
\text { be isolated. }\end{array}$ & $6 \%$ & $96 \%$ \\
\hline $\begin{array}{l}\text { Parents should teach } \\
\text { their children how to } \\
\text { use condoms. }\end{array}$ & $37 \%$ & $63 \%$ \\
\hline $\begin{array}{l}\text { Only promiscuous } \\
\text { people get HIV }\end{array}$ & $5 \%$ & $21 \%$ \\
\hline $\begin{array}{l}\text { A woman has the } \\
\text { right to refuse to } \\
\text { have sex if the } \\
\text { man will not use a } \\
\text { condom }\end{array}$ & $80 \%$ & \\
\hline $\begin{array}{l}\text { The wife/girlfriend } \\
\text { has the right to } \\
\text { refuse to have } \\
\text { sex with her hus } \\
\text { band/boyfriend if she } \\
\text { knows he has } \\
\text { slept with other } \\
\text { women. }\end{array}$ & $79 \%$ & \\
\hline
\end{tabular}

\section{Practices of students on HIV and AIDS}

When asked if they ever had sex or not, 169 of $235(72 \%)$ 
students reported never having sex before while 66 students indicated having sexual intercourse before. Of these 66 students, $30 \%$ indicated that they used condoms always during sexual intercourse, $40 \%$ used it occasionally while $30 \%$ never used condoms. It was also noted that of the 295 students, $71 \%$ had some friends who claimed to have some sexual relationships and about $20 \%$ claimed to use condoms. It was also observed that more than half of the 295 respondents have ever talked to someone about how to avoid contracting Sexually Transmitted Infections (STIs) (78\%), how to avoid pregnancy $(73 \%)$, how to avoid HIV infection $(83 \%)$ and how to use a condom (36\%). Most of these discussed with their peers of the same sex (79\%). Of the 295 students, $32 \%$ reported having an HIV test before.

\section{Discussion}

The study has shown that students are at risk of HIV infection even before they join college. The results agree with Chinese University students who were found to engage in risky behaviours even before joining the university ${ }^{11}$. A study by Ntata and others in 2008 on college students in Zomba, Malawi, found similar results on smoking $(2.7 \%)$ but found higher results on drinking alcohol $(21.5 \%)$ and having multiple sex partners $(40.4 \%)^{12}$. College students are exposed to various factors that put them at risk of contracting HIV. These are peer pressure, lack of maturity, and alcohol and drug use. Although not investigated in the Malawian students; men having sex with men is also among the common risk behaviour among college students ${ }^{13}$. In undergraduate students in China it was revealed that female students are likely to engage in sex and having multiple partners in association with peer pressure, low grades in class, working in places of entertainment, and poor knowledge on sexual behaviour ${ }^{14}$. Most studies which have concluded that a link exists between adolescent and young adult drinking and risky behavior, however, have used global measures of both variables and have not investigated drinking and condom use on the same occasion. If drinking leads to low levels of condom use, both behaviors must occur together. The failure to find that they do simply weakens the hypothesis that they are causally related ${ }^{15,16}$. Abandoning safer sex techniques and failing to use condoms correctly and consistently, can lead to possible infection with HIV or other sexually transmitted diseases ${ }^{17}$.

HIV and AIDS prevention theorists believe that increased knowledge, along with positive attitudes and beliefs about HIV and AIDS, will lead to positive behaviour changes, i.e., behaviours that are less risky, or safer, such as use of condoms, abstinence, and avoidance of risky situations ${ }^{17}$. However, studies indicate that increased knowledge of HIV and AIDS does not always result in a positive behaviour change. Use of alcohol or other drugs often alters judgments about the perceived risks of a particular situation ${ }^{17}$. Increased knowledge due to workshop/course attendance was not related to having an HIV test and also there was no significant relationship found between attending an HIV and AIDS course or workshop. This is supported by Mwale's findings that knowledge is not being translated into substantial behavioural change relative to HIV and AIDS in Malawi in general and Zomba in particular ${ }^{18}$. Risky behaviours like smoking and drinking alcohol were not statistically significantly related to the perception of being at risk and also the taking of an HIV test in this study. The associations might be masked by the fact that all the respondents were educated. This means they have most of the basic knowledge of HIV and AIDS. HIV and AIDS are mainstreamed in the secondary school syllabus.

Though the knowledge was good, some students indicated misconceptions about routes of transmission of HIV and had some erroneous attitudes and beliefs towards AIDS and HIV positive patients i.e. isolating AIDS patients. This confirms that increased knowledge does not always lead to behaviour and attitude change.

Our study suggests that perceptions of being at risk of contracting HIV were associated with risky behaviors. This finding is similar to a study on the Knowledge and attitudes of undergraduate medical and non-medical students in Oman toward Acquired Immune Deficiency Syndrome which found that although most students showed reasonable knowledge regarding transmission, risk behaviors and prevention, misconceptions regarding the attitudes reflected a false perception of the disease among those students ${ }^{19}$. Likewise our study found that, there were some students who seem not to understand whether they are at risk or not i.e. attitudes such as 'only promiscuous people get HIV'. This affect their conceptions about HIV and AIDS risk factors. This lack of knowledge may also be a risk factor to them, as they may contract HIV without information on how they can prevent acquisition.

Although some students felt to be at risk of HIV contraction, others felt not to be at risk mainly because they abstain from sex. Thirty eight (38) of 54 students indicated that they abstain from sex; therefore they are not at risk of contracting HIV in their opinion, contrary to other studies conducted elsewhere ${ }^{20,21,22}$ that found very low percentage of those abstaining. Our study may be similar to a study conducted in China which also found a very low percentage of students who are having sexual intercourse ${ }^{1}$. However, as also noted in the China study, this finding may not be an accurate reflection of the student's sexual behaviors because of self-reported nature of the study. Nevertheless, our study, suggests that being at risk of contracting HIV aids or not may be influenced by whether one was engaged or exposed to risky behaviors at one point of their lives or not.

Other reasons that were identified for not being at risk of HIV contraction included beliefs, being religious and being faithful to one's partner. Students who were religious felt not being at risk of contracting HIV, because they abstain from indulging in sexual intercourse before marriage as prescribed by their religious beliefs. However, this may depend on how one is principled to adhere to such prescriptions. As indicated in Malaysia, a country with the majority of Muslim where, adolescents date and many engage in unsafe sexual intercourse, despite the domination of conservative and traditional values ${ }^{23}$. Most sexual encounters are unsafe, with no protection against STI and unwanted pregnancy. However, like many societies, issues dealing with sex and sexually transmitted infections (STIs) are seen as taboo and sensitive, and therefore are not discussed openly ${ }^{23}$. Therefore, young people may not be well informed and hence are at greater risk of acquiring STIs, particularly HIV.

Nevertheless, our study suggests that being religious may instill some values and principles in people, so that they may not indulge in risky behaviours. This finding is similar to a study in Kuwait that showed that the religious community can play a role in AIDS prevention and control. Having religious values and norms, such as those of Islam may 
invite virtue and abstinence from extramarital sex-one of the main modes of transmission of $\mathrm{HIV}^{24}$. Again, the low prevalence of HIV in Oman is attributed to Islamic religious and cultural factors ${ }^{19}$. However, more studies need to be conducted among different religions to establish how true these findings may be.

\section{Limitations of the Study}

Only one data collection tool, the self-administered questionnaire, was used. There was need to follow-up with series of focus group discussions in order to get clear understanding of the students' attitudes, beliefs and practices. The questionnaire did not cover homosexuality though it is becoming a common topic of discussion in the country. The sampling used was non random and the target was to include all first years, however, this failed because some first years had not arrived and others were occupied with other issues during the time of survey. Despite the sample being non random, we interviewed more than half of the first years.

\section{Conclusion}

The Polytechnic first year students have varying knowledge and practices about HIV and AIDS. There is need to intensify the "WHY WAIT?" training programme to first years during their first week at college. Facilitators of both WHY WAIT and HIV and AIDS module should aim at attitude and behaviour change of students and not just imparting of knowledge. Targeting first year students immediately when they come on the college campus may be effective to reach out to all of them at once before they mingle with continuing students.

There is need to compare these results with other University of Malawi constituent Colleges where similar data was collected.

\section{Acknowledgement}

We would like to thank Professor Moira Chimombo, the Director of Education, SAFE for allowing us to use the data collected before the "WHY WAIT" training course of the first years at the Polytechnic and Mrs Edith Kumwenda for helping in data entry. We would also like to extend our thanks to Dr Adamson Muula and all members of the Editorial Board for their constructive criticisms during compilation of this work.

\section{References}

1. Xiaodong T, Jingju P, Dong Z, Chunhong W, Chaojun X. HIV/ AIDS Knowledge, Attitudes and Behaviors Assessment of Chinese Students: A Questionnaire Study. Int. J. Environ. Res. Public Health. 2007;4(3):248-253.

2. UNAIDS. AIDS epidemic update [Internet]. Geneva, Switzerland: 2007. Available from: www.unaids.org

3. Kelly M, MyiLibrary. What HIV/AIDS can do to education, and what education can do to HIV/AIDS [Internet]. 2000 [cited 2010 May 4];Available from: www.akmearchive.pl/unaids

4. James-Traore TA, Finger W, Ruland CD, Savariaud S. Teacher Training: Essential for School-Based Reproductive Health and HIV/ AIDS Education Focus on Sub-Saharan Africa. Family Health International [Internet]. 2004 [cited 2010 Jun 12];(3). Available from: www.fhi.org/youthnet

5. Chimombo M. WHY WAIT? Truth for Youth; Life Skills Curriculum for Post-Secondary Institutions: Student's Workbook. Zomba, Malawi: Assemblies of God Literature Press; 2005.

6. Bryceson DF, Fonseca J. Risking death for survival: Peasant responses to hunger and HIV/AIDS in Malawi. World Development. 2006 Sep;34(9):1654-1666.

7. AVERT. AVERT-Averting HIV and AIDS [Internet]. AVERT. 2009 [cited 2010 May 12];Available from: www.avert.org

8. UNAIDS. UNAIDS 2008 Report on the global AIDS epidemic [Internet]. Geneva, Switzerland: 2008 [cited 2010 Feb 14]. Available from: www.unaids.org

9. National Statistical Office, ORC Macro. Malawi Demographic and Health Survey [Internet]. Zomba, Malawi: NSO; 2004 [cited 2010 May 3]. Available from: www.nso.malawi.net

10. Guerrero-Lillo L, Medrano-Diaz J, Perez F. Sexual behaviour and knowledge about HIV/AIDS and sexually transmitted infections among health sciences students from Chile. Sex Transm Infect. 2007;83:592593.

11. Ma Q, Ono-Kihara M, Cong L, Xu G, Zamani S, Ravari S, et al. Sexual behavior and awareness of Chinese university students in transition with implied risk of sexually transmitted diseases and HIV infection: a cross-sectional study. BMC Public Health. 2006;18(6):232.

12. Ntata PR, Muula AS, Siziya S, Kayambazinthu E. Gender differences in university students' HIV/AIDS-related knowledge and sexual behaviours in Malawi: a pilot study. Journal of Social Aspects of HIV/AIDS. 2008;5(4):201-205.

13. Raab G, Burns S, Scott G, Cudmore S, Ross A, Gore S, et al. HIV prevalence and risk factors in university students. PUBMED. 1995;9(2):191-7.

14. Yan H, Chen W, Wu H, Bi Y, Zhang M, Li S, et al. Multiple sex partner behaviour in female undergraduate students in China: a multicampus survey. BMC Public Health. 2009;22(9):305.

15. Senf J, Price C. Young adults, alcohol and condom use: what is the connection? J Adolesc Health. 1994;15(3):238-44.

16. Brown J, Vanable P. Alcohol use, partner type, and risky sexual behaviour among college students: Findings from an event-level study. Addict Behav. 2007;32(12):2940-52.

17. CDC pathfinder. HIV/AIDS and College Students [Internet]. 1995 [cited 2010 Feb 10];Available from: www.aegis.com

18. Mwale M. Behavioural Change vis-à-vis Hiv/Aids Knowledge Mismatch among Adolescents: The Case of Some Selected Schools in Zomba. Nordic Journal of African Studies. 2008;17(4):288-299.

19. A.Al-Jabri A, H. Al-Abri J. Knowledge and attitudes of undergraduate medical and non-medical students in Sultan Qaboos.University toward Acquired Immune Deficiency Syndrome. Saudi Medical Journal. 2003;24(3):273-277.

20. Centers for Disease Control and Prevention. Youth Risk Behavior Surveillance-United States. USA: 1997.

21. Mehmet U, Hakan Y. AIDS knowledge and educational needs of technical university students in Turkey. Turkey: 2003.

22. Jinglin H, Hongyuan W, Gang C. Investigation on sexual behavior of college students. J. for STDs and AIDS Prevention and Control. 1997;3:103-105.

23. Wong L, Low W, Jaafar N, Leng Chin C. HIV/AIDS-Related Knowledge Among Malaysian Young Adults: Findings From a Nationwide Survey. Journal of the International AIDS society. 2008;10(6):148.

24. Al-Owaish RA, Moussa MA, Anwar S, Al-Shoumer HA, Sharma P. Knowledge, attitudes, beliefs and practices of the population in Kuwait about AIDS: a pilot study. Kuwait: 1995. 